\title{
Influence of age on response to ipratropium and salbutamol in asthma
}

\author{
MI ULLAH, GB NEWMAN, KB SAUNDERS \\ From the Departments of Medicine and Computer Services, Middlesex Hospital, London
}

\begin{abstract}
We studied the differential response to inhaled salbutamol and ipratropium of 29 asthmatic patients, 18 intrinsic, 11 extrinsic, using peak expiratory flow rate (PEFR), forced expiratory volume in one second $\left(\mathrm{FEV}_{1}\right)$, and forced vital capacity (FVC). Thirty minutes after a theoretically maximally bronchodilating dose of salbutamol $(400 \mu \mathrm{g})$ or ipratropium $(80 \mu \mathrm{g})$, second doses frequently caused further bronchodilatation. We suspect that second doses may reach bronchi untouched by the first inhalation. Analysis of variance showed a powerful intrinsic versus extrinsic effect, and there were clearly differences between patients in their response to treatment (patient versus drug interaction) but these differences were not removed by dividing the patients into intrinsic and extrinsic groups. Results for the group as a whole favoured salbutamol, but examination of individual results by a pattern-recognition technique showed ipratropium equally effective in eight patients and more effective in three. All patients with a definite predominant salbutamol response were less than 40 years old. The response to salbutamol declined significantly with age, whereas that to ipratropium did not. In general in patients aged less than 40 years salbutamol is the drug of choice. With advancing age, and the apparent decline of $\beta$-adrenergic responsiveness, the initially comparatively small response to ipratropium becomes relatively more important and may predominate. In older patients ipratropium, or continued therapy with both drugs, may be preferable.
\end{abstract}

The role of the vagus nerve in clinical asthma presents some controversy. Thus in dogs, allergic asthma has been found to be mediated reflexly, with both afferent and efferent limbs in the vagus nerve. ${ }^{1}$ In patients a role for the vagus nerve has been suggested not only in allergic reactions, but when airway epithelium is eroded by infection, ${ }^{2}$ and irritant gases may have a similar action. ${ }^{3}$ Szentivanyi ${ }^{4}$ on the other hand has postulated a primary defect in the $\beta$-adrenergic system. Parker and colleagues ${ }^{5-7}$ have shown alterations in cyclic AMP metabolism at the cellular level in human bronchial asthma. An initial claim that atropine could completely inhibit antigen-induced bronchoconstriction ${ }^{8}$ has not been confirmed. 910

It seems reasonable therefore to examine the differential response to an atropine-like drug (ipratropium) and a $\beta$-adrenoceptor agonist (salbutamol) in asthmatic patients. If patients responding better to one or the other drug could be identified and classified, this would be relevant to both the aetiology of asthma and its rational treatment.

Address for reprint requests: Dr MI Ullah, The Chest Unit, Heathfield Hospital, Heathfield Road, Ayr KA8 9DZ.

\section{Methods}

Twenty-nine patients who had been shown to increase their $\mathrm{FEV}_{1}$ by at least $15 \%$ in response to isoprenaline inhalation were chosen for this study (table 1). Each patient was assessed before the study by a medical history including a modified MRC questionnaire on respiratory symptoms, physical examination, chest radiograph, and electrocardiogram. Eleven patients were extrinsic asthmatics, defined as having labile airways obstruction ( $>15 \%$ response in $\mathrm{FEV}_{1}$ to a bronchodilator inhalation on at least three occasions), and positive skin-prick test reactions to at least two allergens. Eighteen were intrinsic asthmatics, with a bronchodilator

Table 1 Clinical details of the patients

\begin{tabular}{llc}
\hline & Extrinsic & Intrinsic \\
\hline Number & 11 & 18 \\
Mean age (yr) & 35 & 54 \\
Mean age at onset (yr) & 12 & 47 \\
Mean duration of asthma (yr) & 23 & 7 \\
Chronic cough, sputum & $2 / 11$ & $11 / 18$ \\
Smokers, ex-smokers & $4 / 11$ & $13 / 18$ \\
Atopic family history & $9 / 11$ & $0 / 18$ \\
Positive skin-prick tests & All & None \\
\hline
\end{tabular}


response as above, but no family history of atopy, no allergic rhinitis or eczema, and no positive skinprick tests to a range of 12 common allergens. Patients who were pregnant or who had glaucoma, hepatic, renal, or significant cardiovascular disease were excluded. Patients receiving corticosteroid therapy were not excluded provided the dose had been unchanged for several weeks and was not altered during the study. All other bronchodilator therapy was stopped at least 12 hours before attending the laboratory at mid-day, 1200 hours, each day. Smoking, tea, or coffee were not allowed for at least four hours before and during the assessment. Informed consent was obtained from all the patients and approval of the hospital's ethical committee obtained.

Patients attended the laboratories on two days which were consecutive except in patients receiving alternate day corticosteroids. Each study day began with a 30-minute rest period. Ventilatory function was determined by measuring peak expiratory flow rate (PEFR) with a Wright peak flow meter and forced expiratory volume in one second $\left(\mathrm{FEV}_{1}\right)$ and forced vital capacity (FVC) with a McDermott digital spirometer (Garw Electronics Ltd). Single measurements of PEFR, FEV ${ }_{1}$, and FVC, were made at two-minute intervals during a control period designated AB (see fig 1) of 20 minutes and then four 20-minute experimental measurement periods CD, EF, GH, IJ. The results of the last five measurements for PEFR, FEV ${ }_{1}$, and FVC, from the second half of each experimental period were grouped so that each measurement consists of a mean and standard deviation of PEFR, FEV ${ }_{1}$, and FVC, taken from the second half of these experimental periods. Blood pressure (mean of five measurements over two minutes) and heart rate (mean of 20 measurements over two minutes) from a digital display monitor (Roche) were taken at the end of each experimental period. There are four times of drug administration at $0,30,60$, and 90 minutes (fig 1). Four puffs of the first drug in that day's study was given at 0 minutes followed by a further two puffs at $\mathbf{4 0}$ minutes while the second drug would be given at the same rate at 80 and 120 minutes. Salbutamol was given first on one day, ipratropium on the other, and the order of administration in an individual patient was randomised and double-blind. The dose of salbutamol used was $100 \mu \mathrm{g}$ per puff and for ipratropium $20 \mu \mathrm{g}$ per puff. The response to placebo aerosol using the above format was assessed in six of these patients. Lung volumes were measured by body plethysmography on at least two occasions.

Statistical analyses were performed by Student's paired $t$ test, the Mann-Whitney $U$ test and the chi-square test. An analysis of variance was performed by taking the mean of the last five readings in each experimental section, and defining the sections as control (C) salbutamol (S) and ipratropium (I), we have for each patient

$\mathrm{C}_{1}, \mathrm{I}_{1}, \mathrm{I}_{2}, \mathrm{~S}_{3}, \mathrm{~S}_{4}$ and $\mathrm{C}_{2}, \mathrm{~S}_{1}, \mathrm{~S}_{2}, \mathrm{I}_{3}, \mathrm{I}_{4}$.

The control value $C_{1}$ was subtracted from $I_{1}, I_{2}, S_{3}$ and $S_{4}$, and the control value $C_{2}$ from $S_{1}, S_{2}, I_{3}$ and $\mathrm{I}_{4}$.

We defined the "main effect" of $I$ as

$\left(\mathrm{I}_{1}+\mathrm{I}_{2}\right) / 2-\left(\mathrm{C}_{1}+\mathrm{C}_{2}\right) / 2$.

The "top-up effect" of I as

$\left(\left(I_{2}-I_{1}\right)+\left(I_{4}-I_{3}\right)\right) / 2$,

and the difference between first and second "topup effects" as

$\left(\left(I_{2}-I_{1}\right)-\left(I_{4}-I_{3}\right)\right) / 2$.

We defined the "residual effect" of $I$ as

$\left(\left(S_{3}+S_{4}\right)-\left(S_{1}+S_{2}\right)\right) / 2-2\left(C_{1}+C_{2}\right)$

Here the "top-up" effect refers to increases in periods DF and $\mathrm{HJ}$ described below (table 2) and the "residual effect" to the effect I has when $\mathbf{S}$ is given first. Similar equations were written for the effects of S. F values were calculated with the mean square of patient $\times$ drug interaction rather than the residual mean square.

\section{Results}

PLACEBO STUDIES

Mean PEFR, FEV ${ }_{1}$, and FVC tended to fall over the 140-minute experimental period, with mean falls

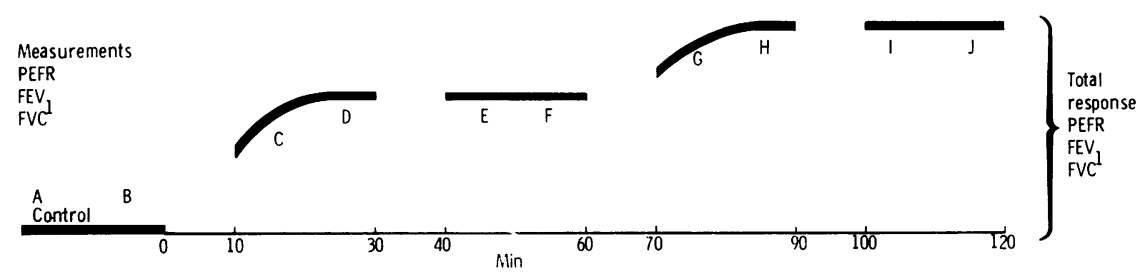

Fig 1 Experimental protocol. See text. 
Table 2 Number of patients (out of total 29) showing significant responses in PEFR and FEV, between various experimental periods (Fig. I)

\begin{tabular}{llllll}
\hline $\begin{array}{l}\text { Number of patients } \\
\text { with significant change }\end{array}$ & \multicolumn{4}{l}{ Comparisons } \\
\cline { 3 - 6 } & B-D & $D-F$ & $F-H$ & $H-J$ \\
\hline $\begin{array}{l}\text { Salbutamol } \\
\text { given first }\end{array}$ & in PEFR & 27 & 18 & 13 & 3 \\
& in FEV & 28 & 19 & 10 & 6 \\
$\begin{array}{l}\text { Ipratropium } \\
\text { given first }\end{array}$ & in PEFR & 24 & 12 & 21 & 14 \\
& in FEV & 21 & 9 & 18 & 19 \\
\hline
\end{tabular}

of 8.7 and $6 \%$ respectively, but these changes were not significant at the $5 \%$ level, either in the group as a whole or in individual subjects.

TIME COURSE OF DRUG RESPONSES

The Mann-Whitney $U$ test was used to distinguish significant changes between experimental periods, using the five measurements from the last 10 minutes of each period. Comparisons BD and FH (table 2) refer to the effect of first and second drug respectively. It had been hoped that few significant changes would be seen in periods DF, $\mathrm{HJ}$ - that is, that a plateau of drug response would have been reached 30 minutes after what was intended as a maximal bronchodilating dose (salbutamol $400 \mu \mathrm{g}$, ipratropium $80 \mu \mathrm{g}$.). In fact (table 2), many patients showed further significant increases during this period.

We next examined changes in mean values for the last 10 minutes of each experimental period, taking the percentage change from the control period and excluding for this purpose five patients whose

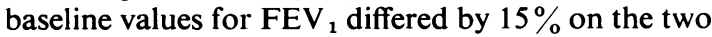
days of study. At 30 minutes ipratropium and salbutamol produced an increase in $F E V_{1}$ of 18 and $34 \%$ respectively (fig $2 \mathrm{~A}$ ), and the differences between drugs were significant $(p<0.01)$. When the second drug was added, salbutamol caused a

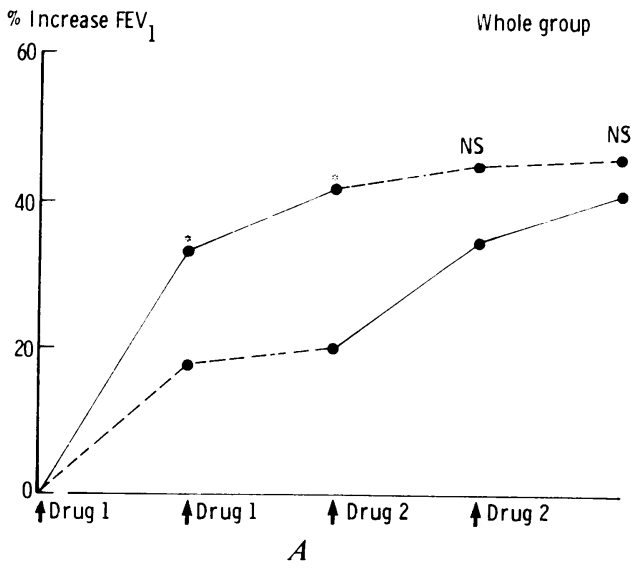

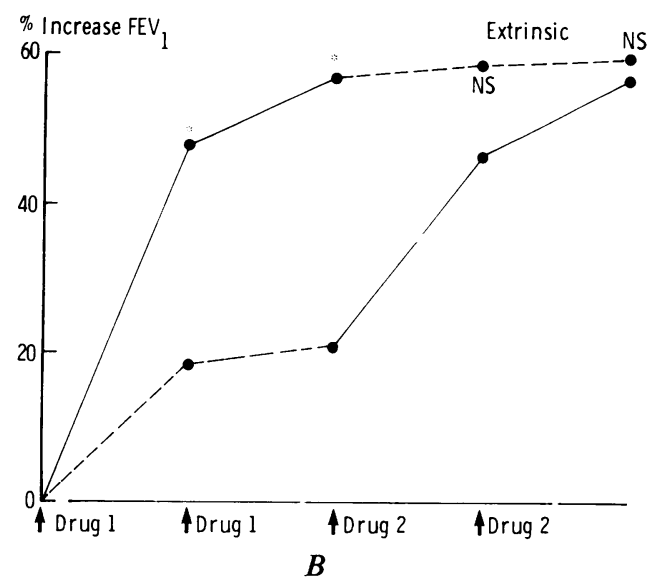
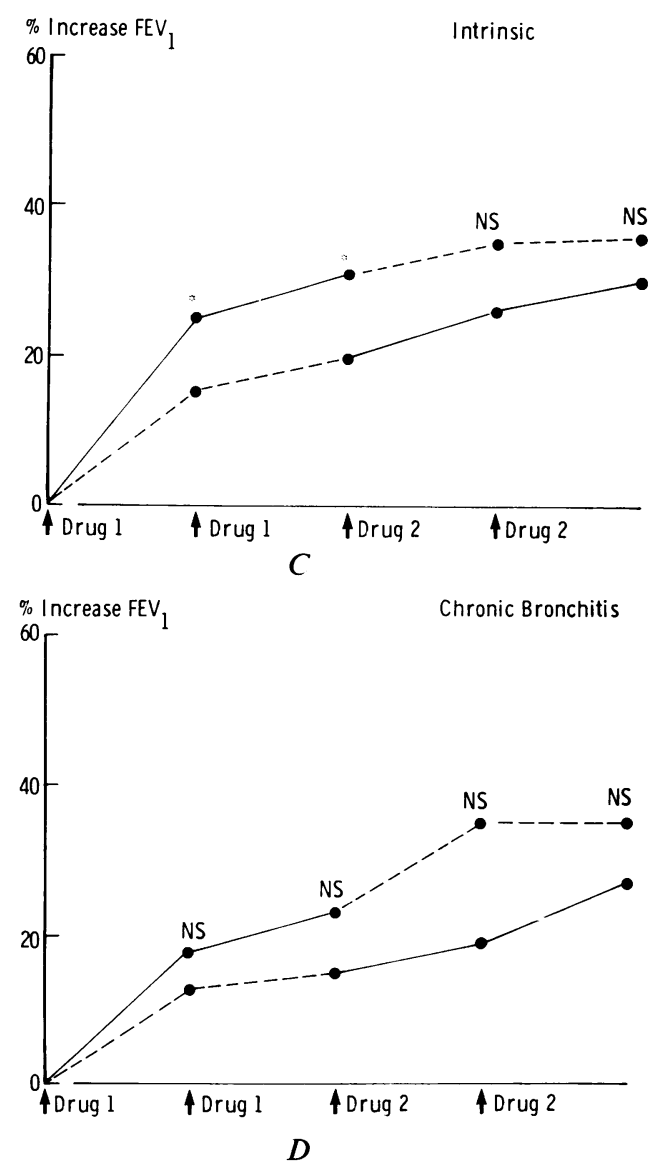

Fig 2 Responses in $F E V_{1}$, percent change from baseline for the whole group $(A)$, extrinsic asthmatics $(B)$, intrinsic asthmatics $(C)$, and subjects with chronic cough and sputum (D). $-=$ salbutamol, - - - = ipratroprium.

Asterisk = significant, $N S=$ insignificant difference between upper and lower lines. 
significant $(\mathrm{p}<0.05)$ increase, whereas ipratropium did not, with the result that at 90 and 120 minutes there was no significant difference between the effects of the combined drugs regardless of order. The divergence between the response lines on fig $2 \mathrm{~A}$ is exaggerated if patients with extrinsic asthma (fig 2B) or patients under 40 years of age are selected, diminished for patients with intrinsic asthma (fig 2C) or patients over 40 years, and even further diminished for patients with chronic cough and sputum (fig 2D) to the extent that there are no significant differences between the response lines. Although in all examples given the final increase in $\mathrm{FEV}_{1}$ was slightly less when ipratropium was given first, this difference was never statistically significant.

Since it appeared (fig 2) that there might be groups of patients responding differently to the drugs, we proceeded to an analysis of variance. Table 3 shows

Table 3 Analysis of variance of PEFR results. F values are calculated using patient $\times$ drug interaction rather than residual mean square except for the patient $\times$ drug interaction itself. All quoted F results are significant at the $1 \%$ level. $N S=F$ valve not significant at $5 \%$ level

\begin{tabular}{lrrc}
\hline & $d f$ & Mean square & \multicolumn{1}{c}{$F$} \\
\hline Drug effects & 7 & 125394 & 24 \\
l vs S & 1 & 109088 & 21 \\
Residual I & 1 & 1 & $(\mathrm{NS})$ \\
Residual S & 1 & 724492 & 137 \\
Top-up I & 1 & 2954 & $(\mathrm{NS})$ \\
Top-up S & 1 & 39361 & $7 \cdot 5$ \\
First vs second top-up I & 1 & 1854 & $(\mathrm{NS})$ \\
First vs second top-up S & 1 & 6 & $(\mathrm{NS})$ \\
Patient effects & 28 & 81254 & 15 \\
Intrinsic vs extrinsic & 1 & 142645 & 27 \\
Patient $\times$ drug interaction & 196 & 5304 & 37 \\
Drug $\times$ intrinsic-extrinsic interaction & 7 & 14570 & $2 \cdot 7$ \\
Residual & 928 & 141 & \\
\hline
\end{tabular}

results for PEFR, and similar results were obtained for $\mathrm{FEV}_{1}$. For the group as a whole the "top-up" and "residual" effects of ipratropium were not significant, whereas those for salbutamol were. This is reflected in the greater number of changes in periods $\mathrm{DF}$ and $\mathrm{HJ}$ for salbutamol in table 2, and the small effect of ipratropium in the upper line in fig $2 \mathrm{~A}$. There is a highly significant difference in the general effects of the two drugs (I versus S), with marked interpatient variation, and a powerful intrinsic versus extrinsic difference. However, the drug $x$ intrinsic-extrinsic interaction has a comparatively small $F$ value.

Thus there were clearly differences between patients in their response to treatment (patient $\times$ drug interaction) but these differences were not removed by dividing the patients into intrinsic and extrinsic groups, although these groups did seem to behave differently.

Intrinsic asthmatics are in general older than extrinsics (table 1). Could the differences be due to age? A second analysis of variance grouping patients as under or over 40 years old gave similar results to the first analysis, since there were only three extrinsics over 40 , and two intrinsics under 40 . On examining these individual results, and the group results from the first analysis of variance, we saw that the three old extrinsics tended to behave like intrinsics, whereas the two young intrinsics behaved like extrinsics.

We therefore devised a second, novel, approach based on pattern recognition to try and take account of individual results and further assess the importance of age versus extrinsic-intrinsic status.

We defined bronchodilator response $(100 \%)$ as the difference between $B$ and $J$ (fig 1), subdivided into effects of the first drug between $B$ and $F$ and of the second drug between $F$ and $J$. These responses could be classified as follows (fig 3): grade Iseven patients had $>75 \%$ of the total response (TR) after salbutamol whatever the order of drug administration; grade II- $>75 \%$ of TR from salbutamol if given first, $25-75 \%$ if given second (11 patients); grade III-between 25 and $75 \%$ of the total response was from salbutamol whatever the order (three patients); grade IV $->75 \%$ of TR from either ipratropium or salbutamol whichever was given first (five patients); grade $\mathrm{V}->75 \%$ of TR from ipratropium if given first, $25-75 \%$ if given second (mirror image of grade II) (three patients); grade $\mathrm{VI} \longrightarrow>75 \%$ total response from ipratropium, whatever the order (mirror image of grade I) (no patients).

For classes I and II, salbutamol is evidently the preferred drug, and for classes $\mathrm{V}$ and VI ipratropium would be the preferable single agent.

From the numbers in the right-hand column of fig 3, a frequency distribution could be obtained, most patients falling in grades I and II. Contingency tables were constructed to analyse the differences between distributions of various possible discriminating categories using the chi-square test. The only significant discriminatory category we could find was the division of patients into age groups above and below 40 years, when all patients in the younger group fell into grade I or II ( $p<0.01$, fig 4).

The following characteristics did not discriminate significantly: extrinsic versus intrinsic; long versus short history of asthmatic symptoms; smokers versus non-smokers; patients with versus those without chronic cough and sputum; on versus not on steroids; on versus not on cromoglycate; atopic versus no atopic family history; pulse rate $<70 \stackrel{\unrhd}{\square}$ versus $>70 / \mathrm{min}$; TLC $>$ versus $<130 \%$ predicted normal; FRC $>$ versus $<175 \%$ predicted normal; $\mathrm{RV}>$ versus $<200 \%$ predicted normal FEV $_{1}<$ 


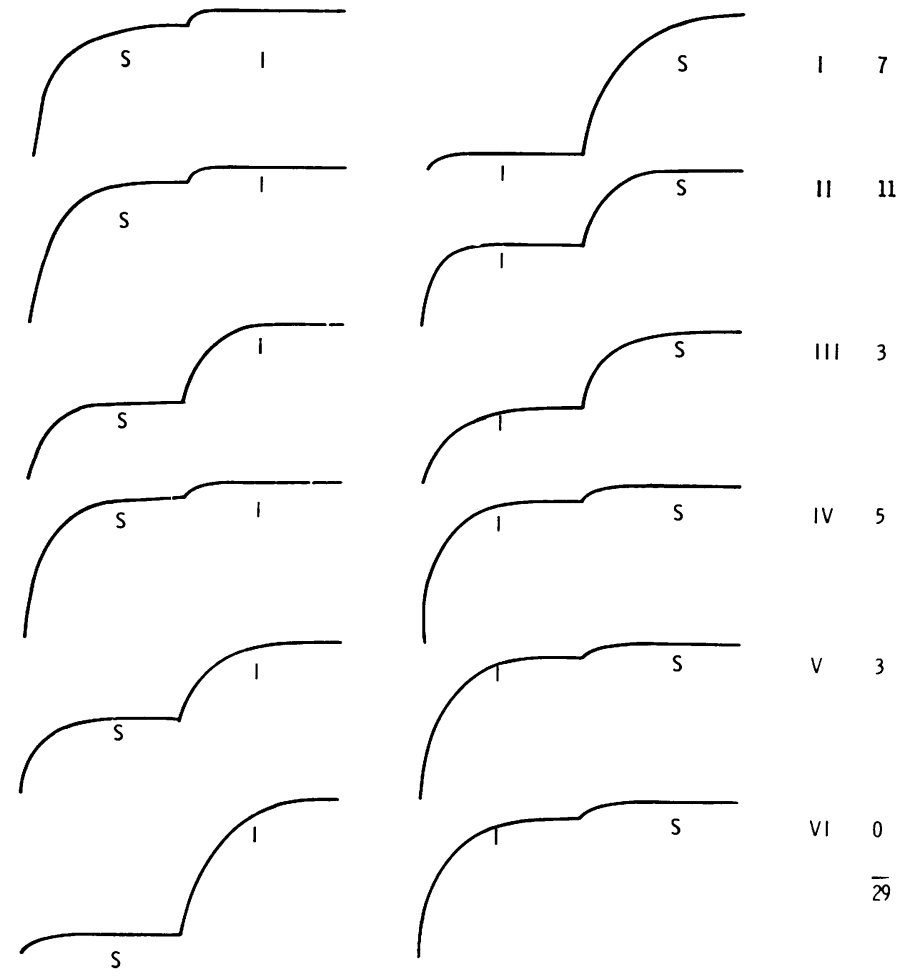

Fig 3 Possible patterns of response in. grades I-VI with salbutamol $(S)$ given first in the left hand column and ipratropium (I) first in the right hand column. Number of patients in each grade is shown at the right margin.

versus $>50 \%$ predicted normal; PEFR $<$ versus $>50 \%$ predicted normal. These findings obtained for both PEFR and FEV 1 results.

\section{PROGRESSIVE CHANGES WITH AGE}

Inspection of the results suggested that on the whole older patients had smaller changes after bronchodilatation, and that this was more marked for salbutamol than ipratropium. This was confirmed by regressing the bronchodilator effect on $\mathrm{FEV}_{1}$ ( $\triangle F E V_{1}$ in litres) against age in years, when there is a significant negative correlation for salbutamol $\Delta \mathrm{FEV}_{1}=-0.012 \times$ age +1.305

but not for ipratropium

$$
r=-0.44 p<0.05
$$

$\Delta$ FEV $_{1}=0.004 \times$ age +0.125

$$
\mathrm{r}=0.19 \mathrm{p}>0.05
$$

DIFFERENTIAL EFFECTS ON FEV 1 AND FVC

Salbutamol $(400 \mu \mathrm{g})$ produced a significantly $(p<0.01)$ greater effect on the FEV 1 than FVC (fig 5), and again after addition of a further $200 \mu \mathrm{g}$ salbutamol, whereas ipratropium produced an equal effect on both indices.

HEART RATE AND BLOOD PRESSURE

Heart rate fell significantly during period $B-D$ (fig 6), but there was no further change thereafter. Neither systolic nor diastolic blood pressure showed significant change.

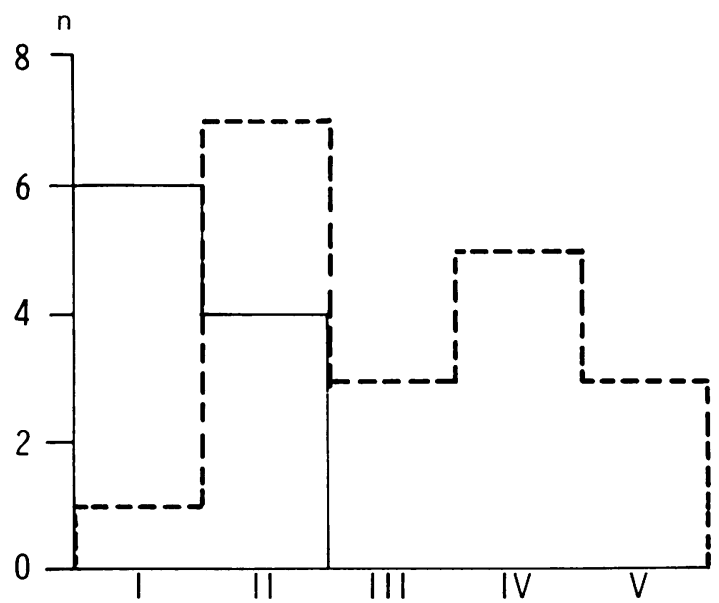

Ipratropium/salbutamol response grade

Fig 4 Distribution of patients over (--.) and under (-) 40 years old in grades I-V( fig 3). Results obtained from PEFR. $p<0.01$. 


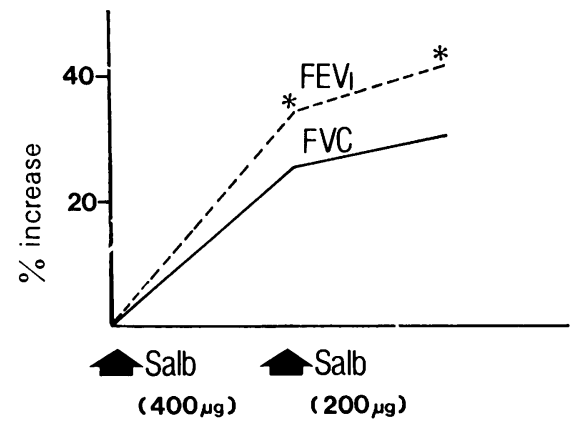

Fig 5 Effect of salbutamol on FEV $V_{1}$ and FVC for the group as a whole. Asterisks signify $p<0.05$ between FEV and FVC.

\section{Discussion}

Initially we gave a dose of $40 \mu \mathrm{g}$ of ipratropium followed by a further $40 \mu \mathrm{g}$ of ipratropium and 200 $\mu \mathrm{g}$ of salbutamol followed by a further $200 \mu \mathrm{g}$ of salbutamol to patients at the points shown in fig 1 . We expected by this to obtain maximum bronchodilatation at the point $D$ with no significant change at $E$ and $F$ so that any subsequent change during $G$ and $\mathrm{H}$ could be put down to the second drug rather than the continued increasing effect of the first drug. Similarly, we hoped to see no significant change between $\mathrm{J}$ and $\mathrm{H}$ confirming that maximal bronchodilatation had occurred. However, many patients showed a significant increase between $B$ and $F$, and $\mathrm{H}$ and $\mathrm{J}$. The initial studies were carried out in the morning beginning at 0900 hours, when spontaneous improvement may occur because of diurnal rhythm. ${ }^{11-13}$ We therefore moved the experiments to the afternoons when spontaneous improvement would be maximal. The increase between $\mathrm{D}$ and $\mathrm{F}$, and $\mathbf{H}$ and $\mathrm{J}$ still occurred. We then considered further that the initial doses of ipratropium $(40 \mu \mathrm{g})$ and salbutamol $(200 \mu \mathrm{g})$ were failing to produce maximal bronchodilatation so we doubled these to

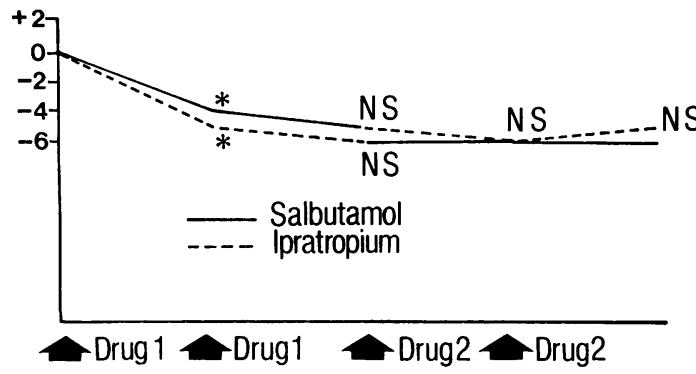

Fig 6 Changes in heart rate. Asterisks signify $p<0.05$ for changes from control. $N S=$ no significant changes thereafter.
$80 \mu \mathrm{g}$ and $400 \mu \mathrm{g}$ of ipratropium and salbutamol respectively.

There seems no reason to doubt that these doses should provide maximum bronchodilation ${ }^{14-17}$ and that a peak or plateau should usually be reached by 30 minutes with both drugs. ${ }^{18} 19$ Yet further significant increases in PEFR and FEV ${ }_{1}$ occurred on many occasions (table 2) especially with salbutamol. The placebo experiments exclude the possibility that such rises are spontaneous and independent of drug action.

We propose that the bronchodilatation produced by the first dose of the drug may allow a second dose to reach bronchi that the first dose cannot reach, thus producing further bronchodilatation even when the first dose was apparently maximal. We stress that we can provide no direct evidence from this study: possibly radioactive tracer techniques could give the answer. It remains an important hypothesis for three reasons. First, it would tend to invalidate the technique of cumulative dose-response in asthmatics, though probably not in normal subjects where distribution of ventilation is more even. Thus Holgate and colleagues ${ }^{20}$ showed that in normal subjects who inhaled salbutamol regularly the effect diminished with time, but curiously were unable to repeat these findings in patients with asthma. ${ }^{21}$ Second, there is a therapeutic implication that two puffs of salbutamol or ipratropium given at the same time might be less effective than one puff followed by a second 20 or 30 minutes later. Similarly, better penetration of beclomethasone dipropionate or sodium cromoglycate might be obtained if preceded 20 or 30 minutes earlier by salbutamol. These points certainly require investigation. Third, it casts considerable doubt on studies where additive or interactive effects are sought between two drugs, if the second drug may be deposited in airways not reached by the first.

The design of this study is unusual in that we made frequent single measurements at regular intervals, rather than taking the best of three attempts at infrequent intervals. This had the advantage that the Mann-Whitney $U$ test could be used to evaluate significant intraindividual effects at each time point.

The analysis by the pattern-recognition method emphasises the importance of examining individual as well as group results. Figure $2 \mathrm{~A}$ suggests that for this group of patients salbutamol is the drug of choice. Yet we were able to show that in eight patients (grades III and IV, fig 3) ipratropium was equally effective and in three patients (grade $\mathrm{V}$ ) more so. Thus in almost $40 \%$ of our patients ipratropium was as effective as or more effective than salbutamol, despite the group mean result. A further advantage of the pattern-recognition technique is 
that taking the total response as $100 \%$, the difficulties of interpatient differences in baseline respiratory function and magnitude of response are avoided.

Our results suggest that the differential response to ipratropium and salbutamol is age-related, although it must be noted that age and intrinsicextrinsic status are closely linked. The response was not related to the duration of asthmatic symptoms, nor to any systematic difference in treatment, and the older patients had in fact asthma of shorter duration (table 1). We found a rather weak but significant negative correlation between the bronchodilator effect of salbutamol and increasing age, but no such correlation for ipratropium. This suggests that whereas in young patients the $\beta$-agonist effect is large compared with the atropine-like effect of ipratropium, the $\beta$-agonist effect declines with age, while the atropine-like effect remains constant, and becomes proportionately more important with age until in some patients ipratropium may be more effective than salbutamol. This might be the result of a progressive decrease of $\beta$-receptor function or a progressive loss of $\beta$-receptors with age as is thought to occur with human cardiac ${ }^{22}$ and neural tissue. ${ }^{23}$ The apparently good response to ipratropium in chronic bronchitis ${ }^{24-26}$ may simply reflect the fact that published series of such patients tend to be older than published series of asthmatics. Our asthmatic patients with chronic cough and sputum showed no difference in distribution across grades I-V compared with patients without those symptoms.

The therapeutic implications are clear. In patients aged less than 40 years, salbutamol is the single drug of choice, though ipratropium may be used if a $\beta$-agonist is for some reason contraindicated. In patients over 40 ipratropium is comparatively increasingly effective, may be used rationally in addition to a $\beta$-agonist, and is in some patients the single drug of choice.

\section{References}

1 Gold WM, Kessler GF, Yu DYC. Role of vagus nerves in experimental asthma in allergic dogs. $J$ Appl Physiol 1972;33:719-25.

2 Empey DW, Laitinen LA, Jacobs L, Gold WM, Nadel JA. Mechanisms of bronchial hyperreactivity in normal subjects after upper respiratory tract infection. $A m R e v$ Respir Dis 1976;113:131-9.

${ }^{3}$ Lee LY, Bleecker ER, Nadel JA. Effect of ozone on bronchomotor response to inhaled histamine aerosol in dogs. J Appl Physiol 1977;43:626-31.

4 Szentivanyi A. The beta adrenergic theory of the atopic abnormality in bronchial asthma. J Allergy $1968 ; 42$ : 203-33.

5 Parker CW, Smith JW. Alterations in cyclic adenosine monophosphate metabolism in human bronchial asthma. I Leukocyte responsiveness to $\beta$-adrenergic agents. J Clin Invest 1973 ;52:48-59.
6 Parker CW, Baumann ML, Huber MG. Alterations in cyclic AMP metabolism in human bronchial asthma. II Leukocyte and lymphocyte responses to prostaglandins. J Clin Invest 1973;52:1336-41.

7 Parker CW, Huber MG, Baumann ML. Alterations in cyclic AMP metabolism in human bronchial asthma. III Leukocyte and lymphocyte response to steroids. $J$ Clin Invest 1973;52:1342-8.

8 Yu DYC, Galant SP, Gold WM. Inhibition of antigeninduced bronchoconstriction by atropine in asthmatic patients. J Appl Physiol 1972;32:823-8.

9 Fish JE, Rosenthal RR, Summer WR, Menkes H, Norman PS, Permutt $S$. The effect of atropine on acute antigenmediated airway constriction in subjects with allergic asthma. Am Rev Respir Dis 1977;115:371-80.

10 Rosenthal RR, Norman PS, Summer WR, Permutt S. Role of the parasympathetic system in antigen-induced bronchospasm. J Appl Physiol 1977;42:600-6.

11 Zedda S, Sartorelli E. Variability of plethysmographic measurements of airway resistance during the day in normal subjects and in patients with bronchial asthma and chronic bronchitis. Respiration 1971 ;28:158-66.

12 Hruby J, Butler J. Variability of routine pulmonary function tests. Thorax 1975;30:548-53.

13 Turner-Warwick M. On observing patterns of airflow obstruction in chronic asthma. Br J Dis Chest 1977;71: 73-86.

14 Baigelman W, Chodosh S. Bronchodilator action of the anticholinergic drug ipratropium bromide (SCH 1000) as an aerosol in chronic bronchitis and asthma. Chest 1977;71:324-8.

15 Gross HJ. Dose response study of the effect of SCH 1000 MDI on forced vital capacity (FVC), FEV , maximal $^{2}$ mid-expiratory flow (MMEF) and heart rate, ECG and blood pressure. Postgrad Med J 1975;51, supplement 7:95-6.

16 Minette A. Ventilatory results and side-effects of salbutamol given by different routes in coalminers with reversible bronchoconstriction. Postgrad Med J 1971; 47, Supplement (March): 55-60.

17 Alliot RJ, Lang BD, Rawson DRW, Leckie WJH. Effects of salbutamol and isoprenaline/phenylephrine in reversible airway obstruction. $B r$ Med J 1972; ; :539-42.

18 Loddenkenpen R. Dose and time response of SCH 1000 MDI on total (Rt) and expiratory (Re) airways resistance in patients with chronic bronchitis and emphysema. Postgrad Med J 1975;51, supplement 7: 97.

19 Walker SR, Evans ME, Richards AJ, Paterson JW. The clinical pharmacology of oral and inhaled salbutamol. Clin Pharmacol Ther 1972;13:861-7.

${ }^{20}$ Holgate ST, Baldwin CJ, Tattersfield AE. $\beta$-adrenergic agonist resistance in normal human airways. Lancet 1977;ii:375-7.

21 Harvey JE, Tattersfield AE. $\beta$-adrenergic responsiveness in asthma. Clin $S c i 1978 ; 54: 24-5 P$.

22 Vestal RE, Wood AJJ, Shand DG. Reduced $\beta$-adrenoceptor sensitivity in the elderly. Clin Pharmacol Ther 1979;26:181-6.

${ }^{23}$ Maggi A, Schmidt MJ, Ghetti B, Enna SJ. Effect of aging on neurotransmitter receptor binding in rat and human brain. Life Sci 1979;24:367-74.

24 Petrie GR, Palmer KNV. Comparison of aerosol ipratropium bromide and salbutamol in chronic bronchitis and asthma. Br Med J 1975;1:430-2.

${ }^{25}$ Leitch AG, Hopkin JM, Ellis DA, Merchant S, McHardy GJR. The effect of aerosol ipratropium bromide and salbutamol in exercise tolerance in chronic bronchitis. Thorax 1978;33:711-3.

26 Douglas NJ, Davidson I, Sudlow MR, Flenley DC. Bronchodilatation and the site of airway resistance in severe chronic bronchitis. Thorax 1979;34:51-6. 